ORIGINAL ARTICLE

\title{
Factors Predicting Responses to HIV/AIDS Prevention Messages among Wollega University Students, Oromia, Ethiopia: A Cross- Sectional Study
}

\author{
Zelalem Desalegn Waktole ${ }^{1 *}$, Ameyu Godesso Roro², LakewAbebeGebretsadik ${ }^{3}$
}

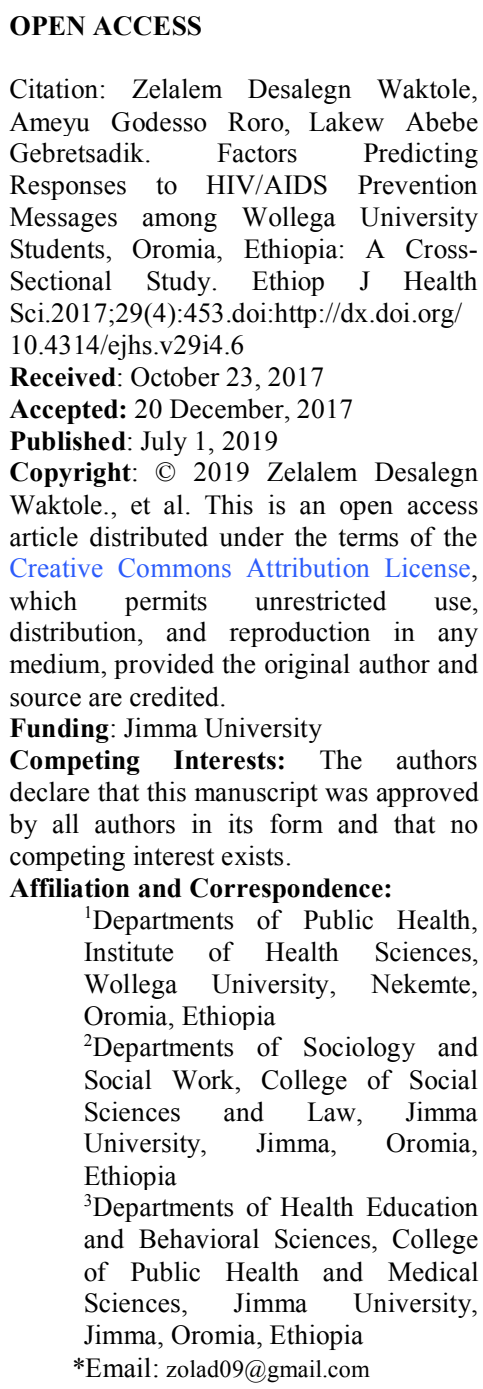

OPEN ACCESS

Citation: Zelalem Desalegn Waktole, Ameyu Godesso Roro, Lakew Abebe Gebretsadik. Factors Predicting Responses to HIV/AIDS Prevention Messages among Wollega University Students, Oromia, Ethiopia: A CrossSectional Study. Ethiop J Health Sci.2017;29(4):453.doi:http://dx.doi.org/ 10.4314/ejhs.v29i4.6

Received: October 23, 2017

Accepted: 20 December, 2017

Published: July 1, 2019

Copyright: (C) 2019 Zelalem Desalegn Waktole., et al. This is an open access article distributed under the terms of the Creative Commons Attribution License, which permits unrestricted use, distribution, and reproduction in any medium, provided the original author and source are credited.

Funding: Jimma University

Competing Interests: The authors declare that this manuscript was approved by all authors in its form and that no competing interest exists.

Affiliation and Correspondence: ${ }^{1}$ Departments of Public Health, Institute of Health Sciences, Wollega University, Nekemte, Oromia, Ethiopia

${ }^{2}$ Departments of Sociology and Social Work, College of Social Sciences and Law, Jimma University, Jimma, Oromia, Ethiopia

${ }^{3}$ Departments of Health Education and Behavioral Sciences, College of Public Health and Medical Sciences, Jimma University, Jimma, Oromia, Ethiopia

*Email: zolad09@gmail.com

\section{ABSTRACT}

BACKGROUND: Since the first HIV/AIDS cases were reported in 1981, HIV has become one of the world's most serious health and development challenges. Messages should be persuasive and appealing in order to bring the desired effect among the target group. This study aims to assess the factors associated with responses to HIV/AIDS prevention messages among university students.

METHODS: A facility based cross-sectional study was conducted using self-administered questionnaire. A total of 710 Wollega University regular students drawn by multi-stage sampling were included. The data were summarized and organized with different descriptive measures and regression analysis using SPSS 16.0.

RESULTS: Six hundred ninety-three (693), 429(61.9\%) male and 264 (38.1\%) female students were participated making a response rate of 97.6\%. The mean age of the respondents was (21.27 1.703$)$ $($ males $=21.60 \pm 1.618 ;$ females $=20.72 \pm 1.701)$. About 252(36.4\%) of the respondents were sexually active, and the mean age of sexual initiation was (18.08 \pm 2.416), male (18.47 \pm 2.294$)$, and female (17.43+2.491). Perceived severity, perceived self and response efficacy of abstinence significantly predicted the current practice of abstinence $\left(R=0.304, a d j R^{2}=0.087\right)$. Perceived self-efficacy of being faithful significantly predicted the current practice of being monogamous $\left(R=0.218, a^{2} R^{2}=0.042\right)$. Perceived self and response efficacy of condom use significantly predicted practice of consistent condom use $\left(R=0.398, a_{j j} R^{2}=0.153\right)$.

CONCLUSION: Perceived self and response efficacy more predicted HIV/AIDS prevention methods than other variables; so an intervention planned targeting those variables would be more successful on HIV/AIDS prevention in the university.

KEYWORDS: HIVIAIDS, Responses,Perceived threat, Efficacy

\section{INTRODUCTION}

Since the first HIV/AIDS cases were reported in 1981, HIV has become one of the world's most serious health and development challenges. UNAIDS reported that globally there were 33.3 million people living with HIV at the end of 2009. Sub-Saharan Africa has only $13 \%$ of the world's population, but home to more than 
two-thirds $(68 \%)$ of people living with HIV which bears an inordinate share of the burden and young people form a significant number in the population $(1,2,3)$. Young people are at the centre of the global AIDS epidemic and of the 1.7 billion young people worldwide; 5.4 million are estimated to be HIV positive. Young people aged 15-24, account for $41 \%$ of new HIV infections (Among those 15 and over) $(1,4)$.

One of the most severe consequences of HIV/AIDS is the loss of young adults in their most productive years, and Ethiopia is one of the most affected countries in East Africa (5,6). HIV/AIDS primarily affects young, with the majority of the victims aged 15-24 years, the bracket under which students in higher institutions lie (7). The high rate of infection among the youth depicts a situation whereby, either the youth have not received sufficient information regarding the dangers associated with the disease, or they have ignored the message (5). Since HIV/AIDS first emerged globally, the role of behaviour change has been recognized as critical to the control of the pandemic and the sentence "Education is the only vaccine against AIDS" was commonly aired to control it(7).

According to Information, Education, and Communication (IEC) model "clear information presented in an appropriate format and language would persuade those at risk to protect themselves from the virus" (8). People want to know more about HIV/AIDS transmission, severity, prevention, treatment and cure from friends, family, and mass media and discuss with health professionals. Then, they will have willing to respond/change their behavior if HIV/AIDS messages are helping them make this change (9). Messages should be persuasive and appealing in order to bring a posetive effect among the target group. A study done in Addis Ababa high schools showed that most HIV/AIDS messages disseminated were not attractive or persuasive and appealing (10). In some cases, even though knowledge and attitudes regarding a health threat and what to do to prevent it can be high, there is still no self-protective behavior (11).

Therefore, this study tried to identify factors associated with responses of university students towards HIV/AIDS prevention messages. Based on identified factors, to recommend appropriate messages preparation.

\section{MATERIALS AND METHODS}

A facility based cross-sectional study was conducted at Wollega University, which is found in Nekemte Town, the capital city of East Wollega Zone in Oromia Regional State from 20-30 February, 2012. The study was conducted among 710 undergraduate regular students from freshman to graduating class. Students who were registered in the second semester in the academic year were included. The sample size was calculated using single population proportion formula $\mathrm{p}=32 \%$ (12) and marginal error (d) $5 \%$ and confidence interval of $95 \%$ which yielded 335 sample sizes. Correction formula was used and yielded 322. A 10\% (33) non-response rate was considered. Using design effects of 2, the final sample size became 710 . From the eight faculties of Wollega University, four were drawn through simple random sampling technique. Then, from each faculty, sample size was determined proportionally from each batch, and study subjects were selected using simple random sampling. Then, from each batches using students identity card as a sampling frame and taking the next student if any withdrawal, dismissal or absent cases faced.

The questionnaire was adapted from similar studies $(12,13)$. It consists of background sexual experiences, perception of susceptibility, severity, response efficacy and self-efficacy, attitude, intention to use HIV/AIDS prevention methods, and practices. A Likert-scale with response options 1-5 points were used. The questionnaire was prepared and administered in English after it was pretested.

The items were adjusted in a way that multiple questions can be collapsed into one or a set of variables whose reliability can be measured. Data were checked for completeness and consistency and analyzed using SPSS 16.0 version. The data were then subjected to factor analysis to know which variables were correlated to be combined to form a single variable in subsequent data analysis. The principal components method of factor analysis and the variables were rotated in factor space

DOI: http://dx.doi.org/10.4314/ejhs.v29i4.6 
using the varimax method of factor rotation. In order to assess the association of factors with outcome of interest, scores in each factor were summed up to come up with a single scoring for each factor for every respondent to represent each factor as single variable in the analysis. The scoring was subsequently reversed for negatively stated statements. Variables that were statistically significant in bivariate analysis were analysed using multiple logistic regressions to examine the predictor variables where the entry value was 0.05 with $95 \%$ CI.

\section{RESULTS}

Characteristics of the respondents: Six hundred ninety three (693) students were participated in this study making the response rate $97.6 \%$. A total of 429(61.9\%) males and $264(38.1 \%)$ females participated in this study. The mean age of the respondents was $(21.27 \pm 1.703)$, male $(21.60 \pm 1.618)$ and female $(20.72 \pm 1.701)$. The respondents were from four faculties, Business and Economics,
147(21.2\%), Natural Science, 130(18.8\%), Technology, $247(35.6 \%)$ and Health Sciences, $169(24.4 \%)$. Then, $224(32.3 \%)$ of them were first year, 179(25.8\%) second year, 159(22.9\%) third year and $131(18.9 \%)$ fourth year. The majority of the respondents, 595(85.9\%) were found in the age group of 20-24, 73(10.5\%) were below 20, and only $25(3.6 \%)$ of them were above 24 . Out of the total respondents, 286(41.3\%) were Orthodox followers, 274(39.5) were protestants, $89(12.8 \%)$ were Muslims, 38(5.5) were Traditional religion followers and $6(0.9 \%)$ were Catholics. Regarding ethnicity of the respondents, $455(65.7 \%)$ were Oromo, 116(16.7\%) Amhara, 32(4.6\%) Tigre, 19(2.7\%) Gurage, $13(1.9 \%)$, Sidama, $6(0.9 \%)$ and $4(0.6 \%)$ were Agew and Wolaita respectively while the others were $48(6.9 \%)$. Almost the majority of the respondents were single, 661(95.4\%), and only $20(2.9 \%)$ and $12(1.7 \%)$ were married but did not live together and married and live together respectively (Table 1).

Table 1: Socio-demographic characteristics of Wollega University students, Oromia, Ethiopia, February, 2012.

\begin{tabular}{llcc}
\hline Variables & & Number & Percentage \\
\hline Sex & Male & 429 & 61.9 \\
age group & Female & 264 & 38.1 \\
& $\leq 19$ & 73 & 10.5 \\
Religion & $20-24$ & 595 & 85.9 \\
& $\geq 25$ & 25 & 3.6 \\
& Orthodox & 286 & 31.3 \\
& Protestant & 274.5 \\
Muslim & Traditional & 12.8 \\
Cthnicity & Catholic & 89 & 5.5 \\
& Oromo & 38 & 0.9 \\
& Amhara & 6 & 65.7 \\
& Tigre & 455 & 16.7 \\
& Gurage & 116 & 4.6 \\
& Sidama & 32 & 2.7 \\
& Agew & 19 & 1.9 \\
& Wolaita & 13 & 0.9 \\
Others** & 6 & 0.6 \\
& Single & 4 & 6.9 \\
& married but not live & 48 & 95.4 \\
& together & 661 & 2.9
\end{tabular}

**kambata, Nuwer, Somale, Shinasha 
Sexual behaviours of the respondents: About $252(36.4 \%)$ of the respondents were sexually active whereas $441(63.6 \%)$ were not. The mean age of sexual initiation of the students was (18.08 \pm 2.416$)$, male $(18.47 \pm 2.294)$, and female $(17.43 \pm 2.491)$. Out of the sexually active students, $79(31.35 \%)$ had regular sexual partners, $39(15.48 \%)$ had occasional sexual partners and $134(53.17 \%)$ did not have sexual partners at all in the last 12 months before data collection. Students' test showed that there was a significant difference between genders in the mean age of sexual initiation $(\mathrm{t}=3.348, \quad \mathrm{DF}=250, \quad \mathrm{p}$ value $=0.001)$. There was no association between having sexual partners in the last 12 months before data collection and gender. Out of those students who were sexually active, 131(51.98\%) had sexual intercourse during the last 12 months before data collection while 121(48.02\%) did not have it. The mean life time sexual partner among sexually active respondents was $(2.30+1.506)$. Among those who had sexual intercourse during the last 12 months before data collection, 23(17.56\%) never used condom, 36(27.48\%) used condom sometimes, $27(20.61 \%)$ used condom most of the times and $45(34.35 \%)$ used condom always. The common reasons why they did not always use condom were trust on partner, 45(25.7\%), disliking condom, 37(21.1\%), being in love with partner, 32(18.3\%), fear that condom reduces pleasure, 24(13.7\%), unavailability of condom, $22(12.6 \%)$, not thinking of it, $10(5.7 \%)$, and partner refusal, $5(2.9 \%)$.Out of those sexually active students, 124(49.2\%) used condom during the first sexual intercourse, and 128(50.8\%) did not use it. During the last time they had sexual intercourse, 111(44\%) used condom and 14(56\%) do not use it (Table 2).

Table 2: Gender comparison of sexually active Wollega University students, Oromia, Ethiopia, February, 2012.

\begin{tabular}{|c|c|c|c|c|c|}
\hline Variables & Male mean(SD) & $\begin{array}{l}\text { Female } \\
\text { mean }(\mathrm{SD})\end{array}$ & $\begin{array}{l}\text { Students' } \mathrm{t}- \\
\text { test }\end{array}$ & DF & p-value \\
\hline Mean age of sexual entrance & $18.47(2.29)$ & $17.43(2.49)$ & 3.348 & 250 & 0.001 \\
\hline Life time sexual partner & $2.22(1.39)$ & $2.44(1.684)$ & 1.262 & 250 & 0.262 \\
\hline last $12 \mathrm{msexual}$ partner & N (\%) & $\mathrm{N}(\%)$ & Chi square & & \\
\hline Regular & $44(27.67)$ & $35(37.63)$ & & & \\
\hline Non regular & $24(15.09)$ & $15(16.13)$ & 3.232 & 2 & \\
\hline No partner & $91(57.23)$ & $43(46.24)$ & & & 0.199 \\
\hline Frequency of condom use & N (\%) & N (\%) & Chi square & & \\
\hline Never used & $16(21.5)$ & $7(13.2)$ & & & \\
\hline Sometimes & $17(21.8)$ & $19(35.8)$ & 4.600 & & \\
\hline Most of the times & $19(24.4)$ & $8(15.1)$ & & 3 & 0.204 \\
\hline Always & $26(33.3)$ & $19(35.8)$ & & & \\
\hline
\end{tabular}

Perceptions about HIV/AIDS infection and prevention methods: Factor analysis of the perceived threat construct showed that $67.511 \%$ of the variance was explained by two components where six items were included $(\mathrm{KMO}=0.500$, $\mathrm{p}<0.001)$. The perception level of threat items (Cronbach's $\alpha=0.642$ ) was found to be low (items mean scores $=2.524 \pm 1.342$ ). Among the respondents, 392(56.6\%) had low score and $301(43.4 \%)$ of them had high perceived threat score, where the mean score of the perceived threat scale was $(15.15+4.412)$. Perceived efficacy of the respondents towards HIV/AIDS prevention methods (Cronbach's $\alpha=0.715$ ) was slightly high (items means score $=3.304+1.27$ ). On the other hand, 371(53.5\%) of the respondents had high score of perceived efficacy towards the HIV prevention methods and $322(46.5 \%)$ of them perceived low score.

Factor analysis of the perceived response efficacy explained $67.149 \%$ of the variance $(\mathrm{KMO}=0.591, \mathrm{p}<0.001)$, where two components were extracted from four items and correlated to explain the response efficacy of the prevention methods. There was no significant mean difference in the response efficacy of HIV/AIDS prevention methods among gender in the student's t-test.The factor analysis of the perceived selfefficacy from eight items, three components that were highly correlated to factor loadings of 
abstinence, being faithful to one partner and consistent condom use were extracted which explained $72.242 \%$ of the variance $(\mathrm{KMO}=0.598$, $\mathrm{p}<0.001)$. Student's t-test shows that there was no significant mean difference between genders with the self-efficacy of HIV/AIDS prevention methods (Data not presented).

\section{Attitude towards HIV prevention methods:}

Four hundred sixty-seven, 467(67.4\%) of the respondents had positive attitude towards abstinence, 265(38.3\%) had positive attitude towards being faithful, 290(41.9\%) had positive attitude towards consistent condom use and majorities 466(67.3\%) had positive attitude towards knowing sero-status (HIV status). There was a significant difference in attitude towards consistent condom use between genders in the student's t-test. $\quad(\mathrm{t}=2.063, \quad \mathrm{DF}=691, \quad \mathrm{p}$ value $=0.039$ ).

Current practices: About 430(62.1\%) of the respondents were protecting themselves by being abstinent, 338(48.8\%) by being faithful to only one partnerand and 179(25.9\%) by using condom consistently. There was a significant mean difference on current practice of consistent condom use among gender using student's t-test $(\mathrm{t}=3.409, \mathrm{DF}=691, \mathrm{p}$-value $=0.001)$.

Intention towards the preventive methods: About $356(51.4 \%)$ of the students had the intention to abstain (item mean score = $3.39 \pm 1.385), 400(57.7 \%)$ had the intention to be faithful to partner by being faithful (mean score $=3.45 \pm 1.301)$ and only $228(32.9 \%)$ had the intention to use condoms consistently (mean score $=2.75 \pm 1.343$ ) the next 12 months. Student's t-test showed that there was no significant difference in intention towards abstinence, being faithful and condom use between genders.

Personal factors associated with prevention methods: Attitude and intention towards abstinence significantly predicted abstinence $\left(\mathrm{R}^{2}=0.162, \mathrm{R}=0.402\right)$. Intention towards being faithful significantly predicted being faithful $\left(\mathrm{R}^{2}=0.054, \quad \mathrm{R}=0.232\right)$. Attitude and intention towards consistent condom use significantly predicted consistent condom use $\left(\mathrm{R}^{2}=0.229\right.$, $\mathrm{R}=0.479$ ) (Table 3).

Table 3: Predictors of the current practices of Wollega University students, Oromia, Ethiopia, February, 2012

\begin{tabular}{|c|c|c|c|c|c|c|c|c|}
\hline \multirow{4}{*}{ Model } & & \multirow{3}{*}{\multicolumn{2}{|c|}{$\begin{array}{l}\text { Unstandardized } \\
\text { Coefficients }\end{array}$}} & \multirow{3}{*}{$\begin{array}{l}\text { Standardized } \\
\text { Coefficients }\end{array}$} & & & \multicolumn{2}{|c|}{$95 \% \quad$ Confidence } \\
\hline & & & & & & & \multicolumn{2}{|c|}{ Interval for B } \\
\hline & & & & & & & Lower & Upper \\
\hline & & B & Error & Beta & $\mathrm{T}$ & Sig. & Bound & Bound \\
\hline \multirow{3}{*}{$\begin{array}{l}\text { 1. abstinent } \\
\mathrm{R}^{2}=0.162 \\
\mathrm{R}=0.402\end{array}$} & (Constant) & 1.948 & .160 & & 12.206 & .000 & 1.635 & 2.261 \\
\hline & Attitude A & .356 & .040 & .341 & 8.960 & .000 & .278 & .434 \\
\hline & \multirow{2}{*}{$\begin{array}{l}\text { Intention A } \\
\text { (Constant) }\end{array}$} & .113 & .037 & .116 & 3.044 & .002 & .040 & .186 \\
\hline $\begin{array}{l}\text { 2.Current being } \\
\text { faithful }\end{array}$ & & 2.245 & .180 & & 12.463 & .000 & 1.891 & S2.599 \\
\hline \multirow{4}{*}{$\begin{array}{l}\mathrm{R}^{2}=0.054 \\
\mathrm{R}=0.232 \\
\text { 3.Current } \\
\text { condom use } \\
\mathrm{R}^{2}=0.229 \\
\mathrm{R}=0.479\end{array}$} & \multirow{2}{*}{$\begin{array}{l}\text { Intention B } \\
\text { (Constant) }\end{array}$} & .230 & .040 & .216 & 5.807 & .000 & .152 & .308 \\
\hline & & 1.048 & .120 & & 8.748 & .000 & .813 & 1.283 \\
\hline & Attitude C & .149 & .039 & .148 & 3.853 & .000 & .073 & .225 \\
\hline & Intention $\mathrm{C}$ & .381 & .038 & .388 & 10.089 & .000 & .307 & .455 \\
\hline
\end{tabular}

Predictors of current Abstinence, Being faithful and Condom use: Perceived severity, perceived self- and response efficacy of abstinence significantly predicted abstinence $\left(R=0.304\right.$, adj $R^{2}$
$=0.087)$. Perceived self-efficacy of being faithful significantly predicted the practice of being monogamous $\left(\mathrm{R}=0.218\right.$, adj $\left.\mathrm{R}^{2}=0.042\right)$. Perceived self- and response efficacy of condom use 
significantly predicted consistent condom use $\quad\left(R=0.398, \quad \operatorname{adj} R^{2}=0.153\right) \quad($ Table 4, 5, 6).

Table 4: Predictors of the current abstinence of Wollega University students, Oromia, Ethiopia, February, 2012

\begin{tabular}{llllll}
\hline Model & \multicolumn{2}{l}{ Un standardized Coefficients } & Standardized Coefficients & & \\
& $\mathrm{B}$ & Std. Error & Beta & $\mathrm{T}$ & Sig. \\
\hline (Constant) & 2.230 & .236 & & 9.446 & .000 \\
perceived severity & -.018 & .023 & -.029 & -.773 & .440 \\
perceived susceptibility & .015 & .024 & .023 & .632 & .527 \\
self-efficacy of A & .114 & .021 & .206 & 5.472 & .000 \\
Response efficacy of A & .189 & .039 & .185 & 4.901 & .000 \\
\hline
\end{tabular}

Table 5: Predictors of the current being faithful of Wollega University students, Oromia, Ethiopia, February, 2012

\begin{tabular}{llllll}
\hline Model & \multicolumn{2}{l}{ Un standardized Coefficients } & \multicolumn{2}{l}{ Standardized Coefficients } & \\
& $\mathrm{B}$ & Std. Error & Beta & $\mathrm{T}$ & Sig. \\
\hline (Constant) & 2.285 & .255 & & 8.946 & .000 \\
perceived severity & -.006 & .024 & -.009 & -.247 & .805 \\
perceived susceptibility & -.024 & .025 & -.036 & -.951 & .342 \\
self-efficacy of B & .114 & .025 & .180 & 4.603 & .000 \\
Response efficacy of B & .078 & .040 & .076 & 1.952 & .051 \\
\hline
\end{tabular}

Table 6: Predictors of the current condom use of Wollega University students, Oromia, Ethiopia, February, 2012

\begin{tabular}{llllll}
\hline Model & \multicolumn{2}{l}{ Un standardized Coefficients } & Standardized Coefficients & T & \multirow{2}{*}{ Sig. } \\
\cline { 2 - 4 } & $\mathrm{B}$ & Std. Error & Beta & & \\
\hline (Constant) & .903 & .223 & & 4.057 & .000 \\
Perceived severity & -.027 & .021 & -.044 & -1.253 & .211 \\
perceived susceptibility & .001 & .023 & .001 & .027 & .979 \\
Self-efficacy C & .232 & .025 & .344 & 9.121 & .000 \\
Response efficacy of C & .073 & .025 & .110 & 2.924 & .004 \\
\hline
\end{tabular}

\section{DISCUSSION}

This study revealed that about $36.4 \%$ of the respondents were sexually active, which is lower than the study of Haramaya and Madawalabu Universities and consistent with the study of Bahir Dar University students $(11,12,13)$. The mean age of sexual initiation of the students of this study was (18.08 \pm 2.416), $18.47 \pm 2.294$ for males and $17.43 \pm 2.416$ for females, which is consistent with other similar studies $(14,15,16)$.

Out of those sexually active students, $53.17 \%$ did not have sexual partners at all in the last 12 months before data collection, which is similar with the study of Bahir Dar University students (14). 31.35\% had regular sexual partner which is lower than the study of Haramaya University and only (15.48\%) had occasional sexual partners. About $61.9 \%$ of the participants in this study experienced having multiple sexual partners, which is double of the study of
Haramaya University (12). Out of those students who were sexually active, $52 \%$ had sexual intercourse during the last 12 months, which is lower than finding from Bahir Dar University students. It is known that having sexual intercourse with multiple sexual partners is highly related with the transmission of HIV/AIDS. This study also found that the mean life time sexual partner was $(2.30+1.506)$ among sexually active respondents, $(2.22+1.390)$ for males and $(2.44+1.684)$ for females, which is consistent with students of Bahir Dar University (14).

Among those who had sexual intercourse during the last 12 months before data collection, $17.56 \%$ never used condom, which is less than half of the study of Haramaya University. 27.48\% used condom sometimes which is consistent with Haramaya University students and still higher number of the respondents on this study (20.61\%) used condom most of the times. $34.35 \%$ used condom always where both are greater than the study of Haramaya University but lower than Bahir Dar

DOI: http://dx.doi.org/10.4314/ejhs.v29i4.6 
University students $(12,14)$. Out of the sexually active students, not more than half $(49.2 \%)$ used condom during their first sexual intercourse, and the number slightly reduced to $44 \%$ during the last time they had sexual intercourse, which is slightly higher than the study of Tanzanian students (17). The reasons might be related with separation from family to study in university which resulted in exposure to and practice of risky behaviors like drugs.

Among the respondents, $56.5 \%$ had low score and $43.5 \%$ of them had high perceived threat score. Even if $36.4 \%$ of the respondents were sexually active, only $18.2 \%$ agreed that there could be the possibility of getting HIV/AIDS, which is lower than that of Bahir Dar University students. This means that almost half of the sexually active respondents perceived risk of infection, but susceptibility item mean score was low $(1.999+1.207)$, which is consistent with students of Bahir Dar University and college students in Midwest $(14,18)$.This could be related to their ignorance. Respondents' perception of severity of HIV/AIDS (items means score $=3.05+1.466$ ) was lower compared to the study done on Bahir Dar University students. This decline may be coincided with availability of VCT and availability of free ART drugs.

In this study, $53.5 \%$ of the respondents had high score of perceived efficacy towards the HIV preventive methods while $46.5 \%$ of them perceived low score (item means score 3.304+1.265) similar with the study of Bahir Dar University (14). More than two third $(67.1 \%)$ of the respondents preferred abstinence as primary effective method with (mean score $=3.81 \pm 1.318)$ and about $(60.6 \%)$ of the respondents preferred being faithful to one partner as the next alternative (mean score $=3.58 \pm 1.355$ ) might be due to the belief they had that marriage can limit the number of partner. About $46.2 \%$ of the respondents agreed to the effectiveness of condom use with perceived response efficacy towards consistent condom use (mean score $=3.16+1.25$ ). This is the lowest when compared to the other preventive methods and consistent with the other studies $(12,15)$. This may be related with their belief that even if they use condom, they might doubt that it is not safe or they may fear that condom can rapture and transmit the virus during sexual intercourse.

The majority (59\%) of the study subjects had selfefficacy towards abstinence with moderate mean score of $(3.48 \pm 1.352)$. The response on self-efficacy on being faithful was relatively high with $60.8 \%$ of the respondents can be able to stick to one partner with mean score $(3.63 \pm 1.248)$. The response of self-efficacy on consistent condom use was low with mean score around the mid (mean score $=2.78+1.232$ ), and $29.7 \%$ of the respondents were able to use condom consistently. In this study, the perception of selfefficacy of condom use is lower than abstinence and being faithful, may be due to lack of confidence to buy condom and fear to ask partner to use condom because it may decrease trust between them.

Attitude towards abstinence was positive with high mean score $(3.80+1.291)$, and the majority $(67.4 \%)$ agreed that abstinence is good. Attitude towards being faithful was also positive (mean score $=3.02 \pm 1.350)$; about (38.3\%) agreed. Attitude towards consistent condom use was positive (mean score $=3.01 \pm 1.309)$ and about $(41.9 \%)$ agreed Generally, attitudes towards each of HIV prevention methods were positive but low towards being faithful and consistent condom use. The reason could be abstinence before marriage is acceptable in most different cultures, norms and religions. About $430(62.1 \%)$ of the respondents protected themselves by being abstinent, $338(48.8 \%)$ by being faithful to only one partner and $179(25.9 \%)$ by using condoms consistently. The reasons of high practices of abstinence could be religious restriction, cultural taboos and fear of sexually transmitted diseases including HIV/AIDS. On the other hand, the low practice of consistent condom use could be associated with risky behaviors like chewing khat, drinking alcohol and smoking cigarette.

The intention of the respondents to be abstinent and faithful in the next 12 months were moderately high while consistent condom use was low. About $41.4 \%$ of the respondents had the intention to be abstinent in the next 12 months with moderately high (mean score $=3.39 \pm 1.385)$. The majority $(57.7 \%)$ of the respondents had the intention to be faithful to one partner in the next 12 months with moderately high rate (mean score $=3.45 \pm 1.301$ ). About $32.9 \%$ of the respondents had the intention to use condom consistently in the next 12 months, which is low compared to abstinence and being faithful (mean score $=2.75 \pm 1.343$ ). The relatively high intention of the majority to be either abstinent or faithful in the next 12 months could be due to the students' behavior change as a result of activities performed by the concerned bodies.

Perceived self- and response efficacy of abstinence significantly predicted the current practice of abstinence. Perceived self- and response efficacy of being faithful significantly predicted the current practice of being faithful. Perceived self- and response efficacy of condom use significantly predicted the current practice of consistent condom use of the 
respondents; these were the better predictors than other variables.

Majority of sexually active respondents experienced having multiple sexual partners. Among those who had sexual intercourse during the last 12 months before data collection, a small number used condom consistently. This needs to reinforce that condom use is safe to prevent HIV/AIDS infection. It is also important to convince the students that HIV/AIDS prevention services are easy to get. Perceived self- and response efficacy are predictors of HIV/AIDS prevention among the study participants.

\section{ACKNOWLEDGEMENTS}

We would like to thank Jimma University for financing this study.

\section{REFERENCES}

1. UNAIDS Report on the global HIV/AIDS epidemic. 2010

2. Population Reference Bureau, World Population Data Sheet; 2010

3. UNAIDS, Report on the global HIV/AIDS epidemic, 2004

4. UNAIDS Report on the global HIV/AIDS epidemic, 2007

5. UNAIDS and World Health Organization (2003), "AIDS Epidemic Update, 2003".

6. UNAIDS, Report on the global HIV/AIDS epidemic, 2002

7. Liskin L, Church CA, Piotrow PT, Harris JA. AIDS Education: a Beginning. Baltimore Centre for Communication Programs, Johns Hopkins School of Public Health, W.DC, USA; 1989; XVII: $1-18$.

8. Focus On HIV/AIDS Communication and Evaluation. November, 26-28, 2001, Managua, Nicaragua Organized by UNFP A with the Rockefeller Foundation, UNESCO, and the Panos Institute, New York: UNFPA, 2001.

9. Piotrow, Kincaid PT, Rimon JD: Health Communication Lessons learned from family planning, JHU, 1996.

10. Cherie A. Perceived sufficiency and usefulness of IEC materials and methods on HIV/AIDS among high school youth in Addis Ababa [Master's Thesis]. Addis Ababa University; 2000.

11. Witte, K. (2001). Managing fear, giving hope: HIV/AIDS and family planning behavior change communication guidelines for urban youth. Addis Ababa, Ethiopia: JHU/CCP and Ethiopia National Office of Population.
12. Beyane N: Predictors of Condom use by using Health belief Model among Haramaya University Students [Master's Thesis]. Haramaya University; 2005.

13. Eticha TB, Bedada DN, Melku TA, Mengistu ST: Risks for STIs/HIV infection among Madawalabu University students, Southeast Ethiopia: a cross sectional study. Reproductive Health 2013;10:38.

14. Shiferaw A: Responses to HIV/AIDS Prevention Messages: based on the extended parallel process model, among Bahir Dar university students, North West Ethiopia [Master's Thesis]. Addis Ababa University; 2004.

15. Governmental, N. (2005) 'HIV / AIDS Awareness Study of Fresh Students in Tertiary Institutions in Rivers State of Nigeria', 140, pp. 6-8.

16. Kibombo R, Neema S, Ahmed HF: Perceptions of risk to HIV Infection among Adolescents in Uganda: Are they Related to Sexual Behavior? African Journal of Reproductive Health 2007; 11[3]:168-181) Makerere Institute of Social Research, Kampala, Guttmacher Institute, New York

17. Adedeji A, Titilayo A, Joseph B, Mainza L: HIV sexual risk behaviors and perception of risk among college students: implications for planning interventions, Midwest, BMC Public Health 2009; 9:281.

18. Amon E, Angelina L, Godfrey M, Khadija K, Godfrey M, Honorati M: Multiple sexual partners and condom use among $10-19$ year-olds in four districts in Tanzania: What do we learn? BMC Public Health 2011;11:490.

DOI: http://dx.doi.org/10.4314/ejhs.v29i4.6 